\section{For Young Consumers Farm-to-fork Is Not Organic: A Cluster Analysis of University Students}

\author{
Ariana Torres \\ Department of Horticulture \& Landscape Architecture and Department of \\ Agricultural Economics, Purdue University, 625 Agriculture Mall Drive, \\ West Lafayette, IN 47907
}

Additional index words. clustering, consumer values, food attributes, Gen Z, Millennials, market segments, ordered logit

\begin{abstract}
Young consumers value healthy foods and are willing to pay for them. As young consumers transition into higher paying jobs, their influence in the food system will compound. This study used a convenient sample of university students to understand how young consumers value attributes for fresh produce. With the proliferation of food labels, this study takes a step back to identify four consumer segments with regard to their values on explicit (i.e., organic and local) and implicit (i.e., small-family farms and sustainable) attributes: committed, farm-to-fork, unattached, and skeptic. The study also investigated the impact of personal motives on cluster membership. Although committed consumers placed high value on all attributes, farm-to-fork consumers valued local, sustainable, and small-family farm systems, but did not have positive valuation toward organic. Our findings suggest increasing access to local foods and farmers market patronage is likely to increase consumers' valuing foods with local, organic, sustainable, and small-family farms attributes.
\end{abstract}

Millennials, the largest living generation, are spending more food dollars in restaurants and convenient meal prepping than previous generations (Stegelin, 2002). This generation is usually described as progressive, open to trying new foods, and valuing sustainable eating (Macke, 2016). Gen Z, those born between 1997 and 2008, are characterized by their health consciousness and social media connectivity (Seemiller and Grace, 2018). As the newest and most ethnically diverse generation, Gen $Z$ consumers have been introduced to healthy lifestyle choices and sustainable living at an earlier age than previous generations (Twenge, 2017). Although there are demographic differences between Millennials and Gen Z, both generations seem to be more knowledgeable than others with respect to food attributes (Harris et al., 2011; Su et al., 2019; Thach and Olsen, 2006)

Americans tend to increase fruit and vegetable consumption with age (USDA-ERS, 2019). As young consumers transition into higher paying jobs and devote more of their income to buying fruits and vegetables (Kuhns and Saksena, 2017), their influence in the food system will only compound.

Received for publication 10 June 2020. Accepted for publication 1 July 2020 .

Published online 6 August 2020.

I thank Madison Turkupolis and Alyssa Moreno for helping with the data collection.

A.T. is an Assistant Professor.

A.T. is the corresponding author. E-mail: torres2@ purdue.edu.

This is an open access article distributed under the CC BY-NC-ND license (https://creativecommons. org/licenses/by-nc-nd/4.0/).
Markets are rarely homogeneous; thus, understanding how young consumers form market segments can help food marketers efficiently target distinct groups of customers and develop long-run relationships (Wedel and Kamakura, 2012). Market segmentation is a common and effective mechanism to target niche markets formed by consumers who think and behave in a similar manner (Foxall and Goldsmith, 1994). Market segmentation can help industry marketers generate appropriate targeting, communication, and encouraging messages to make attribute claims more relevant.

Although labels are commonly used by food marketers to convey information regarding nutrition, origin, and production of foods (Wills et al., 2009), their proliferation seems to be generating skepticism and confusion among consumers (Guilabert and Wood, 2012; Sirieix et al., 2013; VegaZamora et al., 2018). This study takes a step back from the food labeling literature to understand how young consumers value implicit and explicit attributes present in labels for fresh produce (Spence, 2005). Explicit attributes (i.e., organic and local) differ from implicit ones (i.e., small-family farm and sustainable) in that explicit labels are defined by government or third-party organizations (Kuchler et al., 2017) generating a clear understanding on the label (Panzone et al., 2016).

The definition of organic and local produce followed the U.S. Department of Agriculture. Organic fruits and vegetables are those grown in a production system avoiding or excluding the use of synthetic inputs. Local fruits and vegetables were those pro- duced within the state or less than 400 miles. Small-family farm produce was defined as the fruits and vegetables produced in smallscale farms that tend to sell directly to the consumer. Last, the definition of sustainable produce followed Lampkin (1994) as the fruits and vegetables from systems that prioritize the conservation of nonrenewable resources, as well as environmental and social issues.

To illustrate implicit attributes, consumers may be purchasing produce from small-family farms to implicitly support rural economies and the preservation of the environment (Berlin et al., 2009). The fact that consumers tend to implicitly link sustainability to several environmental, ethical, or social issues (Grunert et al., 2014) suggests the importance of sustainable labels in consumer motivation for purchasing fresh produce. Understanding the valuation of implicit and explicit attributes can be helpful for developing both consumer segments and relevant policies, incentives, and strategies.

Building from the theories of reasoned action (Bang et al., 2000) and intention and behavior (Fishbein and Ajzen, 1975), this study proposes that understanding how young consumers value produce attributes can help predict their attitudes and purchasing intentions. Supplying foods with attributes that align with consumers' values can help food marketers develop trust relationships that extend beyond the first purchase (Yue and Tong, 2009). This is especially important if we consider that building loyalty with younger consumers may have a longterm impact for food retailers.

Using a convenient sample of young consumers, this study investigated how their valuation of organic, local, sustainable, and small-family produce attributes can be segmented into actionable groups that are similar within but different between one another. Although most young adults favor attributes that convey environmental and social benefits, marketing strategies and policies will likely have opposing effects for different groups of consumers. Food marketers should develop specific marketing messages when catering to young consumers. This study complements previous research with a comprehensive empirical analysis that identified different young consumer segments with regard to their values on attributes for fresh produce. This study also contributes to the literature by providing the main factors driving young consumers to be part of each market segment. First, a two-stage cluster analysis process provided four distinct segments of young consumers. Second, an ordered logit model investigated the influence of demographics, purchasing behavior, and community involvement on segment membership.

\section{Consumers' Values and Attitudes}

Previous studies have shown how well values correlate with attitudes and buying behavior. Heo and Muralidharan (2019) 
reported Millennial consumers who valued environmental issues were more likely to buy products with labels that convey sustainability. Zepeda and Deal (2009) reported that shopping for organic foods is likely motivated by consumer's values and beliefs. The same researchers found that buying local foods provides a sense of community involvement to those spending dollars, a sentiment that seems to be invoked by farmer-consumer trust relationships. This grower-consumer relationship, built commonly in local markets, appears to influence the presence of price premiums for local, organic, and sustainable food products (Torres et al., 2016). These trends suggest young consumers adopt sustainable consumption patterns to impact food systems with their dollar spending (Dobson, 2007) and their attitudes influence their demand of different food labels (Panzone et al., 2016).

Researchers have reported the strong connection between messages that convey how foods are produced and marketed and consumers' values and attitudes (Heo and Muralidharan, 2019; Hu et al., 2011; Lusk, 2018; Zepeda and Deal, 2009). Among all food attributes, explicit (i.e., organic and local) and implicit (i.e., sustainable and small-family farms) attributes are gaining attention among Americans (Darby et al., 2008; $\mathrm{Hu}$ et al., 2011). The discussion on consumers' preferences for local and organic attributes has gained much attention among researchers and industry stakeholders. On the one hand, organic food sales continue to grow by double-digit rates, currently accounting for $\approx \$ 35$ billion in sales in 2017 (USDANASS, 2019). On the other hand, the interest in local foods from consumers, producers, and policymakers seems to be growing, reflected by increases in the number of farmers markets and food sales through local markets (Low et al., 2015). Some studies have claimed that consumers' preferences for local is higher than organic foods (Bazzani et al., 2017; Meas et al., 2014), whereas others report that claims complement each other (Costanigro et al., 2014; Hempel and Hamm, 2016). Although most research has focused on consumer choices between local and organic, fewer studies have found that consumers also value and are willing to pay price premiums for alternative attributes in food products, such as sustainable and small-family farms ( $\mathrm{Hu}$ et al., 2011; Meas et al., 2014; Verain et al., 2012). The fact that implicit and explicit labels may lead to different behavior has important implications for researchers and industry stakeholders (Panzone et al., 2016).

\section{Consumer Segments}

Markets are rarely homogeneous, and market segmentation is a common and effective mechanism to reach groups of consumers who think and behave in a similar manner. Cluster analysis has been widely used to segment consumers based on their values and attitudes (Knuth et al., 2019). Verain et al. (2012) provided a review of the seg- ments formed by sustainable food consumer literature. Following an overview of 16 articles, they reported the existence of three general consumer segments based on their values toward food attributes, including green segment, potential green segment, and nongreen segment based on consumers' scores for high, medium, and low for environmental attitudes, respectively. Chryssohoidis and Krystallis (2005) segmented consumers into loyal, explorers, health conscious, and independent clusters based on the frequency of organic purchases. D'Souza et al. (2006) interviewed supermarket shoppers and reported the existence of two segments of consumers for sustainable products composed of the environmentally green and price-sensitive green consumer. Yue et al. (2010) clustered consumers between 20 and 86 years old into three market segments regarding their purchases of organic and conventional potatoes: industry trusting, healthy oriented, and price-oriented consumers. Koutsimanis et al. (2012) identified two market segments among consumers of fresh produce. Identifying marketable clusters enables business managers to target specific products to consumers most likely to purchase them.

Important profiling variables in consumer segmentation are sociodemographic and behavioral characteristics. Women and men tend to have different preferences regarding different types of food purchase. Most studies have associated women often placing a higher value on sustainable, local, and organic foods (Verain et al., 2012; Yue et al., 2010; Zepeda and Deal, 2009). Level of educational attainment seems to be positively correlated with acquiring information and making food purchases that favor local, organic, sustainable, and small-family farm attributes (Behe et al., 2013; Panzone et al., 2016; Zepeda and Deal, 2009). In segmenting consumers with respect to their values toward food attributes, researchers have found inconsistencies between income and purchasing of foods with environmental and social attributes (Verain et al., 2012; Zepeda and Deal, 2009). Thus, it is important to include sociodemographic characteristics in a market segmentation analysis.

Although several studies evaluated how American consumers value food labels, only a few have looked into Gen Z and Millennial consumers and their valuation for implicit and explicit attributes. Recently, Su et al. (2019) segmented Gen Z consumers based on their environmental values as activists, believers, and moderates. Kumar and Smith (2018) reported that Millennials and Gen $\mathrm{Z}$ comprise the generations favoring local foods the most. This article contributes to the literature segmenting these young consumers regarding their values of common attributes for fresh produce, and provides the main drivers and barriers to segment membership.

\section{Data and Methodology}

Data description. Data for this analysis come from a 2017 Web-based survey of university students. Using data from a survey of university students provides a convenient sample of young consumers, many of whom are considered more knowledgeable than noncollege young people with respect to their preferences for explicit and implicit attributes present in foods (Harris et al., 2011). The development of the questionnaire was informed by a review of the literature and interviews with students, buyers, and vendors at farmers markets, and food marketers. Pretesting techniques included direct observation of the answering process, focus groups, and experts' review of the questionnaire (Groves et al., 2011). For example, a pretest questionnaire was administered to 20 university students between 1 and 15 Mar. 2017, and researchers tabulated the frequency that respondents interrupted, repeated, refused, or requested clarification.

Surveying university students provides a convenient sample to investigate young consumers' perceptions toward produce attributes. Similar studies have used this type of convenient sampling to collect primary data (Heo and Muralidharan, 2019; Ness et al., 2002; Vecchio and Annunziata, 2013). The questionnaire and survey protocol were approved by the institutional review board for compliance with ethical standards for human subjects research. The final version of the questionnaire was delivered on 29 Mar., via e-mail through the Office of the Registrar online database of $\approx 41,000$ students at the university. Access to the Registrar's office database facilitated the access to the entire list of e-mail addresses of university students. The invitation e-mail included the link for the Qualtrics survey. To increase participation rate, a drawing of ten $\$ 5$ gift cards was offered for those who completed the survey before 5 Apr. 2017. A total of 2047 responses were received, of which 1954 responses were completed surveys, for a $5 \%$ response rate.

The questionnaire covered four common thematic areas of a student's valuation of fresh produce attributes. Specifically, the questionnaire asked students to report the importance they place on fresh produce attributes such as organic (ORGANIC), local (LOCAL), sustainable (SUSTAINABLE), and small-family farms (SMALL). The survey asked respondents' perceptions toward the importance of produce attributes by asking them to slide bars from 0 (not important) to 100 (very important). Slider bars is an interactive tool to capture respondents' perceptions in a more engaging survey experience, more mobile friendly, and may produce superior data, than the traditional Likert-like scales (Buskirk, 2015; Roster et al., 2015). The questionnaire included 21 questions that ranged from student demographics to the respondent's involvement in extracurricular activities. Last, the questionnaire included questions on consumption, growing, and purchasing of fresh produce.

To obtain a clear analysis of young American clusters, the subsample excluded staff and respondents who were not uniquely selfreported as undergraduate students. The 
subsample focused on 1351 undergraduate students enrolled in 2017 at a large Midwestern university. Table 1 illustrates the demographic characteristics of the survey respondents. Of 1351 students, 385 (29\%) were freshmen, 352 (26\%) were sophomores, 304 (22\%) were juniors, and 313 (23\%) were seniors. The proportion of students by year of enrollment was consistent with records of the student population for 2017 (data from personal interview with Admissions officer).

Methodology. To understand better how Millennials and Gen $\mathrm{Z}$ consumers form clusters with respect to the importance they place on fresh produce from organic, local, sustainable, and small-family farming systems, a scatterplot matrix was used to obtain a graphic display of the data. Pairwise variable correlations were examined showing that collinearity was not an issue in the cluster analysis. To illustrate, the highest correlation was obtained at 0.55 between variables $L O$ $C A L$ and SMALL. The data were analyzed using Stata (release 15; StataCorp, College Station, TX).

Cluster analysis has been widely used to define consumer segments based on their characteristics (Behe et al., 2013; Heng and House, 2018). Segments of young consumers with similar perception functions were identified using a cluster analysis performed in a two-stage process. First, a hierarchical clustering with Ward's minimum-variance method was used to analyze the relative factor score for LOCAL, ORGANIC, SUSTAIN$A B L E$, and $S M A L L$ using the squared Euclidean distance as the (dis)similarity measure. Ward's linkage combined observations whose merger increased the overall within-cluster variance (i.e., the homogeneity of clusters) to the smallest possible degree. The number of clusters was determined by a combination of Duda-Hartand index, Kalinksi/Harabasz pseudo F-index, and $\omega_{k}$ criterion. Taking indices together, the author selected a four-cluster solution that minimized $\omega_{k}$.
The second step in the cluster analysis included a partitioning $k$-means method, using the grouping from the Ward's linkage analysis as input for the starting partition of clusters. The $k$-means method selected the centers of the initial clusters from the first observations and assigned the other observations to the nearest cluster with the aim of minimizing the within-cluster variation. The $k$-means process was repeated until convergence was achieved. This study explored the overlap in the two cluster procedures (Ward's linkage and $k$-means) using a cross tabulation. Results showed that there is a strong degree of overlap ( $>80 \%$ ) between the two cluster procedures, suggesting a robust fourcluster solution. Clusters were profiled using a one-way analysis of variance (ANOVA) comparison of means. ANOVA results confirmed that attribute differences in means were significant across clusters.

An ordered logit model investigated the impact of demographics, purchasing behavior, and community involvement on consumer segments. The ordered logit is an appropriate framework to model cluster membership where the observed variable has natural ordering (Greene, 2008). Based on Table 2, this study assumed that cluster membership follows a natural order, in which individuals in the committed cluster (first cluster) had high expectations for all four attributes, followed by the farm-to-fork cluster (second cluster) valuing produce grown by sustainable, local, and small-family operations, but not organic. The unattached cluster (third cluster) was composed of consumers placing importance values to attributes between the second and fourth cluster. Last, skeptic clusters had low valuation for all attributes (fourth cluster).

The ordered logit model is based on random utility theory, which assumes that individuals choose the alternative that would give them the highest level of utility. The ordered logit is based on a latent continuous variable
$Y^{*}$ underlying the ordinal clusters observed. The latent variable is a linear combination of vector characteristics $(X)$ describing the individual, a set of parameter vectors $(\beta)$, and an error term $\varepsilon$ assumed to have a standard logistic distribution. Letting $i=1,2, \ldots, j$ index of clusters, and for the case of four clusters (i.e., $y_{i} \in[1,2,3,4]$ ):

$$
y_{i}^{*}=X_{i} \beta+\varepsilon_{i}
$$

The unobserved latent variable is $y_{i}^{*}$ and $y_{i}$ is the observed ordinal variable:

$$
\begin{aligned}
& y_{i}=1 \text { if } y_{i}^{*} \leq \kappa_{1} \\
& y_{i}=2 \text { if } \kappa_{1}<y_{i}^{*} \leq \kappa_{2} \\
& y_{i}=J \text { if } y_{i}^{*} \kappa_{J-1}
\end{aligned}
$$

Consequently,

$$
\operatorname{Pr}\left[y_{i}=j\right]=\operatorname{Pr}\left[y^{*} \text { is in the } j\right. \text { th range }
$$

Hence, the probability of observing an outcome can be written as follows:

$\operatorname{Pr}\left[y_{i}=j\right]=F\left[\kappa_{J}-\beta^{\prime} X_{i}\right]-F\left[\kappa_{J-1}-\beta^{\prime} X_{i}\right]$,

where $\mathrm{F}()=.\exp () /.[1+\exp ()$.$] , implying that$

$$
\operatorname{Pr}\left[y_{i}=j\right]=\frac{1}{1+e^{-\kappa_{J}+\beta^{\prime} X_{i}}}-\frac{1}{1+e^{-\kappa_{J-1}+\beta^{\prime} X_{i}}},
$$

which were used to derive the maximum likelihood estimates of $\kappa$ and $\beta$.

\section{Results}

Descriptive statistics. Table 1 describes the descriptive statistics of the demographic characteristics of the sample, including their perceived importance on organic, local, sustainable, and small-family farm produce attri-

\begin{tabular}{|c|c|c|c|c|}
\hline Variable & Obs. & Mean & $\mathrm{SD}$ & Description \\
\hline ORGANIC & 1281 & 55.50 & 28.14 & Importance placed on organic farming, from 0 (not important) to 100-point scale (very important) \\
\hline LOCAL & 1333 & 72.55 & 23.88 & Importance placed on local farming, from 0 (not important) to 100 -point scale (very important) \\
\hline SUSTAINABLE & 1343 & 78.50 & 22.50 & Importance placed on sustainable farming, from 0 (not important) to 100 -point scale (very important) \\
\hline SMALL & 1335 & 71.01 & 25.18 & Importance placed on small-family farming, from 0 (not important) to 100 -point scale (very important) \\
\hline FRESHMEN ${ }^{\mathrm{z}}$ & 1351 & 0.29 & 0.45 & $1=$ if student is freshman, 0 otherwise \\
\hline SOPHOMORE ${ }^{z}$ & 1351 & 0.26 & 0.44 & $1=$ if student is sophomore, 0 otherwise \\
\hline $\mathrm{JUNIOR}^{\mathrm{z}}$ & 1351 & 0.22 & 0.42 & $1=$ if student is junior, 0 otherwise \\
\hline SENIOR $^{z}$ & 1351 & 0.23 & 0.42 & $1=$ if student is senior, 0 otherwise \\
\hline STORE $^{z}$ & 1351 & 97.19 & 16.54 & $1=$ if student buys most fruits and vegetables in a chain store, 0 otherwise \\
\hline FARMERSMKT ${ }^{z}$ & 1351 & 44.26 & 49.69 & $1=$ if student buys most fruits and vegetables in farmers markets, 0 otherwise \\
\hline $\mathrm{GROW}^{\mathrm{z}}$ & 1351 & 1.92 & 13.74 & $1=$ if student grows fruits and vegetables, 0 otherwise \\
\hline AGBACKGROUND ${ }^{z}$ & 1351 & 27.17 & 44.50 & $1=$ if student was raised with an agricultural background, 0 otherwise \\
\hline FEMALE $^{\mathrm{z}}$ & 1348 & 59.64 & 49.08 & $1=$ if student is female, 0 otherwise \\
\hline AGE & 1343 & 20.24 & 1.62 & Age of student in years \\
\hline INVOLVED $^{z}$ & 1351 & 52.18 & 49.97 & $1=$ if student is actively seeking opportunities for campus/community involvement, 0 otherwise \\
\hline MIDWEST $^{z}$ & 1349 & 0.63 & 0.48 & $1=$ if student is from Midwest, 0 otherwise \\
\hline OUT-MIDWEST ${ }^{z}$ & 1349 & 0.31 & 0.46 & $1=$ if student is from out-of-Midwest, 0 otherwise \\
\hline INTERNATIONAL ${ }^{\mathrm{z}}$ & 1349 & 0.06 & 0.23 & $1=$ if student is international, 0 otherwise \\
\hline ONCAMPUS $^{z}$ & 1350 & 50.44 & 50.02 & $1=$ if student lives on-campus housing, 0 otherwise \\
\hline AGMAJOR $^{z}$ & 1351 & 14.06 & 34.78 & $1=$ if student is enrolled in the College of Agriculture, 0 otherwise \\
\hline
\end{tabular}
butes. Our empirical analysis of 1351 college students revealed that respondents value attributes related to produce differently. The most

Table 1. Descriptive statistics and description of the demographic and behavioral variables for the full sample of 1532 university students participating in an online survey about the importance of fresh produce attributes $(\mathrm{N}=1532)$.

${ }^{\mathrm{z}}$ The mean is the percentage of respondents with that attribute. 
Table 2. Mean comparisons of clusters of 1532 university students participating in an online survey on the importance of organic, local, sustainable, and small-family attributes. Values are from 0 (not important) to 1 (very important) point scale $(\mathrm{N}=1532)$.

\begin{tabular}{lccccr}
\hline & \multicolumn{4}{c}{ Cluster } & Total \\
\cline { 2 - 5 } & Committed & Farm-to-fork & Unattached & Skeptic & $0.25 \mathrm{D}$ \\
ORGANIC & $0.80 \mathrm{~A}^{\mathrm{z}}$ & $0.30 \mathrm{C}$ & $0.66 \mathrm{~B}$ & $0.256 .35 \mathrm{D}$ & 0.73 \\
LOCAL & $0.90 \mathrm{~A}$ & $0.78 \mathrm{~B}$ & $0.66 \mathrm{C}$ & $0.35 \mathrm{C}$ & 0.79 \\
SUSTAINABLE & $0.91 \mathrm{~A}$ & $0.86 \mathrm{~A}$ & $0.69 \mathrm{~B}$ & $0.54 \mathrm{C}$ & 0.71 \\
SMALL & $0.88 \mathrm{~A}$ & $0.83 \mathrm{~B}$ & $0.54 \mathrm{C}$ & $0.40 \mathrm{D}$ & 1273 \\
N. Obs. & 426 & 336 & 333 & 178 & 14 \\
Market size (\%) & 33 & 27 & 26 & 14 & \\
\hline
\end{tabular}

${ }^{\mathrm{z}}$ Upper case letters show statistically significant differences across columns at the $P<0.01$ using Tukey's significant difference test.

important produce attribute was sustainable $(79 \%)$, followed by local $(73 \%)$, and smallfamily farms $(71 \%)$. The fact that sustainable produce placed highest among all attributes suggests the importance of understanding the implicit impact of sustainable labels in food systems. Interestingly, organic produce was the least important for students, as they placed an average importance of 56\%. Most students $(97 \%)$ in the sample buy fruits and vegetables from grocery stores, $44 \%$ buy from farmers markets, and only $2 \%$ of students grow some produce.

Fewer than a third of students in our sample were raised with an agricultural background, and $\approx 60 \%$ were female. The percentage of female students in our sample was higher than the $43 \%$ of female students enrolled as undergraduates in 2017. Researchers have reported the higher online survey participation rate of women than men in university environments (Smith, 2008). Approximately half of respondents were actively seeking opportunities for campus or community involvement, which may be explained by their participation in the community. Fifty percent of students lived in on-campus housing, 14\% were enrolled in the College of Agriculture, and $\approx 94 \%$ of students were domestic (63\% from the Midwest and $31 \%$ from outside the Midwest).

Cluster analysis. The study conducted a cluster analysis to explore whether market segments exist within our sample of university students. Using cluster analysis with respondents' values for local, organic, sustainable, and small-family farm attributes, four clusters were produced. Statistical tests (Table 2) illustrate the mean differences across clusters at the $1 \%$ level. Table 3 illustrates the demographic characteristics for each consumer segment.

Cluster 1, the largest segment, represents $33 \%$ of the sample (426 students). Cluster 1 (labeled committed) strongly valued all four produce attributes as important, as evidenced by the highest average values across all attributes (within column) (Table 2). The committed segment was composed of a higher share of Millennials and Gen $\mathrm{Z}$ consumers purchasing in farmers markets $(53 \%)$, being female (69\%), seeking opportunities for campus/community involvement (59\%), being Midwest or international students, and living in on-campus housing (Table 3 ).
Cluster 2 consisted of $27 \%$ of the sample. Consumers in the second cluster, labeled farm-to-fork, had high preference for attributes commonly related with local food systems, such as local, sustainable, and smallfamily farming, but not with organic farming (Table 2). Other researchers have reported how the corporatization of organic markets is likely to drive consumers and producers away from organic food products (Hu et al., 2011; Torres and Marshall, 2018). The farm-to-fork is composed of individuals with an agricultural background (47\%), coming from Midwestern states (74\%), and enrolled in an agricultural major (28\%) (Table 3). Although the committed and farm-to-fork segments are different, Millennials and Gen $\mathrm{Z}$ consumers in the farm-to-fork cluster shared some demographic similarities with consumers in cluster 1. For example, they reported a similar shopping behavior, as well as their proportion of women, involvement in campus/ community events, and on-campus housing.

Cluster 3 consists of $26 \%$ of the sample (333 students). Consumers in the third cluster (labeled unattached) had moderate expectations for all features, and did not show high preferences for any of the attributes. This group had a mean score intermediate between cluster 2 and cluster 4 for most variables (Table 2). To illustrate, $39 \%$ of consumers in this group purchased at farmers markets, $53 \%$ were female, and $56 \%$ were from the Midwest (Table 3 ). These unattached consumers were characterized by actively seeking campus/community involvement activities, being international, and living in on-campus housing. Last, cluster 4, labeled skeptic, consists of $14 \%$ of the sample (178 students). The skeptic segment was the smallest group and was composed of consumers who did not express high expectations in general. Consumers in this group scored the lowest on purchasing in farmers markets, lacked an agricultural background, and reported being international or not from the Midwest (Table 3).

Ordered logit analysis. The ordered logit provided the results of cluster membership among young consumers with regard to their values on food trends. Results from a Brant test showed that the ordered model meets the proportional odds assumption, and an insignificant $\chi^{2}$ suggested that the model assumptions were met, thus validating the use of an ordered logit regression. Table 4 illustrates the marginal effects of the ordered logit for each cluster membership: committed, farm-tofork, unattached, and skeptic. The marginal effects provide the impacts of explanatory variables on consumer segments. Results suggest that demographics, purchasing behavior, and community involvement are key drivers of cluster membership.

Student's year in the undergraduate program significantly impacted cluster membership $(P<0.05)$. For example, sophomore students were $4 \%$ more likely to be associated with both unattached and skeptic clusters, and $7 \%$ and $0.7 \%$ less likely to be associated with committed and farm-to-fork segments, relative to freshmen students. Similarly, Detre et al. (2010) reported that freshmen students were more likely to prefer organic and local produce. Such results can be supported by previous findings that suggest the increasing expenditures due to moving out of university accommodation after the first year, typically to achieve a more independent lifestyle, can drive sophomore students to prioritize price than other food attributes to diminish food expenses (Ness et al., 2002). A Pearson's $\chi^{2}$ test showed that, in effect, $90 \%$ of freshmen lived on campus, compared with $55 \%$ of sophomore $(P<0.05)$.

As previously documented by the literature, purchasing behavior is a major factor influencing individuals' preferences and values toward food systems (Feldmann and Hamm, 2015). Drawing from theories of reasoned action (Bang et al., 2000) and intention and behavior (Fishbein and Ajzen, 1975), values and beliefs toward food can help predict the food choices and purchasing behavior of Millennials and Gen $\mathrm{Z}$ individuals. In other words, we could expect that high personal values toward organic agricultural systems can predict committed individuals purchases to be mainly organic. Our results suggest that purchasing behavior seems to be a major factor impacting Millennial and Gen Z membership in customer segments. Purchasing produce from farmers markets is associated with an $11 \%$ likelihood to be part of the committed cluster $(P<0.01)$. Similarly, having an agricultural background increases the likelihood of being associated with the committed $(9 \% ; P<0.01)$. Last, actively seeking involvement with the community positively influences the likelihood to be a member of the committed cluster $(6 \%$; $P<0.01)$. It seems that the linkage between people growing food and choosing produce to buy increases the likelihood of Millennials and Gen $\mathrm{Z}$ to be in the committed or farm-tofork clusters.

Our results suggest gender is correlated with the likelihood of valuing local, organic, sustainable, and small-family farm attributes in fresh produce. Female students were 13\% and $1 \%$ more likely to be part of the committed and farm-to-fork segment, respectively $(P<0.01)$. It has been documented by the literature that women tend to have more positive attitudes and preferences toward local and organic foods (Feldman and Hamm, 2015), which may be a mechanism to 
Table 3. Descriptive statistics of the demographic and behavioral variables for the four clusters of 1532 university students participating in an online survey about the importance of fresh produce attributes. ${ }^{z}$

\begin{tabular}{|c|c|c|c|c|c|c|c|c|}
\hline & \multicolumn{2}{|c|}{ Committed $^{\mathrm{y}}$} & \multicolumn{2}{|c|}{ Farm-to-fork } & \multicolumn{2}{|c|}{ Unattached } & \multicolumn{2}{|c|}{ Skeptic } \\
\hline & $\overline{\text { Mean }}$ & SD & Mean & SD & Mean & SD & Mean & SD \\
\hline$\overline{\text { FRESHMEN }}^{\mathrm{x}}$ & 0.33 & 0.47 & 0.26 & 0.44 & 0.29 & 0.46 & 0.26 & 0.44 \\
\hline SOPHOMORE $^{\mathrm{x}}$ & 0.23 & 0.42 & 0.27 & 0.44 & 0.28 & 0.45 & 0.29 & 0.45 \\
\hline JUNIOR $^{x}$ & 0.23 & 0.42 & 0.19 & 0.39 & 0.21 & 0.41 & 0.25 & 0.43 \\
\hline SENIOR $^{x}$ & 0.21 & 0.41 & 0.29 & 0.45 & 0.22 & 0.42 & 0.21 & 0.41 \\
\hline STORE $^{\mathrm{x}}$ & 0.97 & 0.16 & 0.98 & 0.15 & 0.97 & 0.16 & 0.96 & 0.21 \\
\hline FARMERSMKT $^{\mathrm{x}}$ & 0.53 & $0.50 \mathrm{~A}$ & 0.49 & $0.50 \mathrm{~A}$ & 0.39 & $0.49 \mathrm{~B}$ & 0.26 & $0.44 \mathrm{C}$ \\
\hline GROW $^{\mathrm{x}}$ & 0.02 & 0.15 & 0.02 & 0.14 & 0.00 & 0.00 & 0.02 & 0.13 \\
\hline AGBACKGROUND $^{\mathrm{x}}$ & 0.24 & $0.43 \mathrm{BC}$ & 0.47 & $0.50 \mathrm{~A}$ & 0.13 & $0.33 \mathrm{C}$ & 0.16 & $0.37 \mathrm{C}$ \\
\hline FEMALE $^{\mathrm{x}}$ & 0.69 & $0.46 \mathrm{~A}$ & 0.65 & $0.48 \mathrm{~A}$ & 0.53 & $0.50 \mathrm{~B}$ & 0.44 & $0.50 \mathrm{~B}$ \\
\hline AGE & 20.23 & 1.76 & 20.36 & 1.58 & 20.14 & 1.54 & 20.26 & 1.62 \\
\hline INVOLVED $^{x}$ & 0.59 & $0.49 \mathrm{~A}$ & 0.51 & $0.50 \mathrm{~A}$ & 0.53 & $0.50 \mathrm{~A}$ & 0.41 & $0.49 \mathrm{~B}$ \\
\hline MIDWEST $^{\mathrm{x}}$ & 0.62 & $0.49 \mathrm{BC}$ & 0.74 & $0.44 \mathrm{~A}$ & 0.56 & $0.50 \mathrm{~B}$ & 0.57 & $0.50 \mathrm{~B}$ \\
\hline OUT-MIDWEST $^{x}$ & 0.31 & $0.46 \mathrm{AB}$ & 0.25 & $0.44 \mathrm{~B}$ & 0.35 & $0.48 \mathrm{~A}$ & 0.38 & $0.49 \mathrm{~A}$ \\
\hline INTERNATIONAL $^{\mathrm{x}}$ & 0.08 & $0.27 \mathrm{~A}$ & 0.01 & $0.11 \mathrm{~B}$ & 0.10 & $0.30 \mathrm{~A}$ & 0.05 & $0.22 \mathrm{~A}$ \\
\hline ONCAMPUS $^{x}$ & 0.53 & $0.50 \mathrm{AB}$ & 0.44 & $0.50 \mathrm{~B}$ & 0.56 & $0.50 \mathrm{~A}$ & 0.46 & $0.50 \mathrm{~B}$ \\
\hline AGMAJOR $^{x}$ & 0.10 & $0.30 \mathrm{~B}$ & 0.28 & $0.45 \mathrm{~A}$ & 0.06 & $0.24 \mathrm{~B}$ & 0.09 & $0.29 \mathrm{~B}$ \\
\hline N. Obs. & & 426 & & 336 & & 333 & & 178 \\
\hline Market size (\%) & & 33 & & 27 & & 26 & & 14 \\
\hline
\end{tabular}

${ }_{\mathrm{z}}$ Identification of the optimal number of clusters was based on both objective (i.e., numerous clustering algorithm) and subjective criteria.

${ }^{y}$ Upper case letters show statistically significant differences across clusters at the $P<0.1$ using Tukey's significant difference test.

${ }^{\mathrm{x}}$ The mean is the percentage of respondents with that attribute.

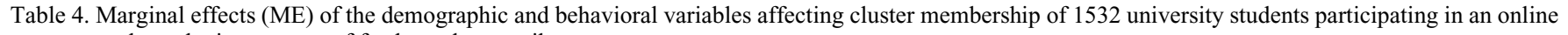
survey about the importance of fresh produce attributes.

\begin{tabular}{|c|c|c|c|c|c|c|c|c|}
\hline & \multicolumn{2}{|c|}{ Committed } & \multicolumn{2}{|c|}{ Farm-to-fork } & \multicolumn{2}{|c|}{ Unattached } & \multicolumn{2}{|c|}{ Skeptic } \\
\hline & $\mathrm{ME}$ & $\mathrm{SE}$ & $\mathrm{ME}$ & SE & $\mathrm{ME}$ & $\mathrm{SE}$ & $\mathrm{ME}$ & $\mathrm{SE}$ \\
\hline SOPHOMORE & -6.98 & $3.41 * *$ & -0.68 & 0.42 & 4.08 & $1.99 * *$ & 3.59 & $3.50 * *$ \\
\hline JUNIOR & -3.95 & 4.26 & -0.22 & 0.28 & 2.29 & 2.47 & 1.87 & 35.20 \\
\hline SENIOR & -4.16 & 5.06 & -0.24 & 0.35 & 2.42 & 2.94 & 1.98 & 41.50 \\
\hline STORE & -0.83 & 6.96 & -0.08 & 0.70 & 0.49 & 4.08 & 0.43 & 90.50 \\
\hline FARMERSMKT & 11.11 & $2.34 * * *$ & 1.12 & $0.42 * * *$ & -6.51 & $1.43 * * *$ & -5.72 & $0.00 * * *$ \\
\hline GROW & 13.20 & 9.70 & 1.33 & 1.06 & -7.74 & 5.70 & -6.80 & 17.40 \\
\hline AGBACKGROUND & 8.72 & $2.68 * * *$ & 0.88 & $0.40 * *$ & -5.11 & $1.61 * * *$ & -4.49 & $0.10 * * *$ \\
\hline FEMALE & 12.88 & $2.35 * * *$ & 1.30 & $0.47 * * *$ & -7.55 & $1.46^{* * *}$ & -6.63 & $0.00 * * *$ \\
\hline $\mathrm{AGE}$ & 1.34 & 1.09 & 0.13 & 0.12 & -0.78 & 0.64 & -0.69 & $21.90 * * *$ \\
\hline INVOLVED & 6.30 & $2.41 * * *$ & 0.64 & $0.31 * *$ & -3.69 & $1.43 * * *$ & -3.24 & 0.90 \\
\hline OUT-MIDWEST & -2.28 & 2.51 & -0.27 & 0.33 & 1.34 & 1.48 & 1.21 & 37.30 \\
\hline INTERNATIONAL & 2.47 & 5.25 & 0.13 & 0.16 & -1.43 & 3.03 & -1.16 & 62.20 \\
\hline ONCAMPUS & 1.00 & 2.82 & 0.10 & 0.29 & -0.59 & 1.66 & -0.52 & 72.30 \\
\hline AGMAJOR & -1.86 & 3.27 & -0.19 & 0.33 & 1.09 & 1.92 & 0.96 & 57.00 \\
\hline
\end{tabular}

Number of observations $=1265$. Prob $>\chi^{2}=0.00$. Pseudo $R^{2}=0.09$. MEs are expressed in percentage points. $* * * P<0.01, * * P<0.05$.

be more socially and environmentally aware of their food choices.

\section{Discussion and Conclusions}

Americans are spending more on fruits and vegetables than ever before. Theories such as reasoned action and intention and behavior propose consumers' purchasing behavior for fresh produce is driven by the attitudes they place on their foods (Bang et al., 2000; Fishbein and Ajzen, 1975; Zepeda and Deal, 2009). Several researchers have investigated how understanding consumer attitudes toward food labels can help predict and motivate purchasing behavior. Because of the confusion and skepticism generated by the proliferation of food labels, this study takes a step back from the food labeling literature to understand how explicit and implicit attributes in fresh produce may be driving young consumer behavior. Few studies have focused on the value that Gen Z and Millennial consumers place on fresh produce with organic, local, sustainable, and small-family farming attributes. Moreover, it is unknown how these young consumers can be segmented into actionable groups that are similar within but different between.

This research study was one of the first of its kind to explore the values of young consumers regarding the four most common implicit and explicit attributes in fresh produce. Using data from a survey of university students provides a convenient sample of Millennial and Gen $\mathrm{Z}$ consumers. As the two most health-conscious and consumptionoriented generations, the influence of Millennials and Gen $\mathrm{Z}$ is shaping food trends in America (Harris et al., 2011). The importance of these two generations lies on their purchasing power, their influence in family purchases, and the long-run relationships they establish with brands and food attributes (Thach and Olsen, 2006). Thus, it is crucial that researchers, food retailers, and industry stakeholders understand the key factors influencing Millennial and Gen Z purchasing behavior.
The main contribution of this article is the market segmentation of young consumers based on their personal values toward explicit (i.e., organic and local) and implicit (i.e., small-family farming and sustainable) attributes for fresh produce. Four distinct segments of young consumers were obtained using a two-stage cluster analysis: committed, farm-to-fork, unattached, and skeptic. The committed cluster is composed of individuals who placed high value on all attributes: organic, local, sustainable, and small-family farming systems. Committed consumers were characterized by shopping in local markets, being female, and looking for involvement in the community.

The farm-to-fork segment is composed of consumers who valued local, sustainable, and small-family farm systems, but did not have positive attitudes toward organic produce. The findings suggest a lack of trust of the organic label by an important segment of young consumers. Consistent with studies on local food systems (Meas et al., 2014; Torres et al., 2016), it seems that young consumers 
substitute the organic label with local and sustainable attributes present in fresh produce. The fact that an important segment of the population does not seem to value organic foods presents important implications for food marketers and other stakeholders promoting organic foods.

First, food safety recalls, along with distrust of big corporations entering the organic industry, seem to be leading young consumers to prefer produce with attributes that convey sustainability, localness, and small farming (Hu et al., 2011). Policymakers and food marketers wanting to increase the market share of organic foods should adopt labeling schemes that build trust in the organic label. For example, providing information about the farm origin and agricultural practices can convey the impact of purchasing organic foods in local and farming communities. This is especially true as Vilella-Vila et al. (2005) suggested that increasing consumers' knowledge regarding agricultural practices can increase the importance of food attributes. In addition, retailers can use the organic seal in conjunction with multiple labels, figures, and messages that convey transparency about how the product was produced, including environmental and social features. Examples may include information on carbon footprint, lack of pesticide use, or protection to pollinators.

Second, it is likely that farm-to-fork consumers in the study choose to value local foods to help support farmers and impact local food systems with their spending. Our results are consistent with other studies reporting consumers placing value on local apples (Costanigro et al., 2011; Onozaka and Mcfadden, 2011), apple sauce (James et al., 2009), blackberry jam (Meas et al., 2014), plants (Behe et al., 2013), potatoes (Loureiro and Hine, 2002), and food in general (Adams and Salois, 2010; Bellows et al., 2008).

Our findings suggest increasing access to local foods and farmers market patronage is likely to increase consumers' valuing foods with local, organic, sustainable, and smallfamily farm attributes. From a marketing standpoint, this information can be used by farmers selling directly to consumers to understand what Millennials and Gen $Z$ consumers value and how they choose to spend their money. Understanding that young consumers prefer produce from local, sustainable, and small-family farming to impact local communities can help retailers develop messages and strategies that build long-term loyalties. Developing the correct messages that appeal to this niche market can also assist food growers, processors, and retailers to better position their business in a competitive environment.

Results suggest that cluster membership is driven by personal motives, particularly, the desire to contribute to the local food system and supporting local communities. Specific drivers that increase consumer values for local, organic, sustainable, and small-family farm produce attributes included demographic, purchasing behavior, and percep- tions. Shopping in local markets, being female, and involvement in the community were the most important factors driving young consumer valuation for produce attributes. It seems that highlighting family and farm stories can help young consumers become part of the committed market segment. Farmers can further lead consumers to learn more about their story via Web sites, newsletters, and social media.

This study offers some important information on clustering young consumers attending university. One possible limitation of the study is that the dataset was limited to undergraduate students located in a Midwestern university. Future research should look at a nationwide sample of Millennial and Gen Z consumers to identify how their food values influence their perceptions and purchasing behavior. Future research should also increase the number of questions capturing consumption, purchasing behavior, and perceptions for fresh produce.

\section{Literature Cited}

Adams, D.C. and M.J. Salois. 2010. Local versus organic: A turn in consumer preferences and willingness-to-pay. Renew. Agr. Food Syst. 25(04):331-341.

Bang, H., A.E. Ellinger, J. Hadjimarcou, and P.A. Traichal. 2000. Consumer concern, knowledge, belief, and attitude toward renewable energy: An application of the reasoned action theory. Psychol. Mark. 17(6):449-468.

Bazzani, C., V. Caputo, R.M. Nayga, Jr., and M. Canavari. 2017. Revisiting consumers' valuation for local versus organic food using a nonhypothetical choice experiment: Does personality matter? Food Qual. Prefer. 62:144-154.

Behe, B.K., B.L. Campbell, C.R. Hall, H. Khachatryan, J.H. Dennis, and C. Yue. 2013. Consumer preferences for local and sustainable plant production characteristics. HortScience 48(2):200-208.

Bellows, A.C., B. Onyango, A. Diamond, and W.K. Hallman. 2008. Understanding consumer interest in organics: Production values vs. purchasing behavior. J. Agr. Food Ind. Organ. 6:1-31.

Berlin, L., W. Lockeretz, and R. Bell. 2009. Purchasing foods produced on organic, small and local farms: A mixed method analysis of New England consumers. Renew. Agr. Food Syst. 24(4):267-275.

Buskirk, T.D. 2015. Are sliders too slick for surveys? An experiment comparing slider and radio button scales for smartphone, tablet and computer based surveys. Methods, Data, Analyses 9(2):229-260.

Chryssohoidis, G.M. and A. Krystallis. 2005. Organic consumers' personal values research: Testing and validating the list of values (LOV) scale and implementing a value-based segmentation task. Food Qual. Pref. 16(7):585599 .

Costanigro, M., S. Kroll, D. Thilmany, and M. Bunning. 2014. Is it love for local/organic or hate for conventional? Asymmetric effects of information and taste on label preferences in an experimental auction. Food Qual. Prefer. 31:94-105.

Costanigro, M., D. Thilmany, S. Kroll, and G. Nurse. 2011. An in-store valuation of local and organic apples: The role of social desirability. Agribusiness 27(4):465-477.
Darby, K., M.T. Batte, S. Ernst, and B. Roe. 2008. Decomposing local: A conjoint analysis of locally produced foods. Amer. J. Agr. Econ. 90(2):476-486.

Detre, J.D., T.B. Mark, and B.M. Clark. 2010. Understanding why college-educated millennials shop at farmers markets: An analysis of students at Louisiana State University. J. Food Distrib. Res. 41(3):14-24.

Dobson, A. 2007. Environmental citizenship: Towards sustainable development. Sustainable Dev. 15(5):276-285.

D’Souza, C., M. Taghian, and P. Lamb. 2006. An empirical study on the influence of environmental labels on consumers. Corp. Comm.: An Inter. J. 11:162-173.

Feldmann, C. and U. Hamm. 2015. Consumers' perceptions and preferences for local food: A review. Food Qual. Prefer. 40:152-164.

Fishbein, M. and I. Ajzen. 1975. Intention and behavior: An introduction to theory and research. Addison-Wesley, Reading, MA.

Foxall, G.R. and R.E. Goldsmith. 1994. Consumer psychology for marketing. Routledge, London, U.K

Greene, W.H. 2008. Econometric analysis. Prentice Hall, Upper Saddle River, NJ.

Groves, R.M., F.J. Fowler, Jr., M.P. Couper, J.M. Lepkowski, E. Singer, and R. Tourangeau. 2011. Survey Methodology. Vol. 561. John Wiley \& Sons, Hoboken, NJ.

Grunert, K.G., S. Hieke, and J. Wills. 2014. Sustainability labels on food products: Consumer motivation, understanding and use. Food Policy 44:177-189.

Guilabert, M. and J.A. Wood. 2012. USDA certification of food as organic: An investigation of consumer beliefs about the health benefits of organic food. J. Food Prod. Mktg. 18(5): 353-368.

Harris, K.J., J. Stiles, and J. Durocher. 2011. A preliminary evaluation of the millennial shopping experience: Preferences and plateaus. Hospitality Rev. 29(1):24-47.

Hempel, C. and U. Hamm. 2016. How important is local food to organic-minded consumers? Appetite 96:309-318.

Heng, Y. and L.A. House. 2018. Cluster analysis for fruit consumption patterns: An international study. Brit. Food J. 120(9):1942-1952.

Heo, J. and S. Muralidharan. 2019. What triggers young Millennials to purchase eco-friendly products? The interrelationships among knowledge, perceived consumer effectiveness, and environmental concern. J. Mktg. Commun. 25:421-437.

Hu, W., M.T. Batte, T. Woods, and S. Ernst. 2011 Consumer preferences for local production and other value-added label claims for a processed food product. Eur. Rev. Agr. Econ. 39(3):489510 .

James, J.S., B.J. Rickard, and W.J. Rossman. 2009. Product differentiation and market segmentation in applesauce: Using a choice experiment to assess the value of organic, local, and nutrition attributes. Agr. Resource Econ. Rev. 38(3):357-370.

Knuth, M., B.K. Behe, C.R. Hall, P.T. Huddleston, and R.T. Fernandez. 2019. Sit back or dig in: the role of activity level in landscape market segmentation. HortScience 54:1818-1823.

Koutsimanis, G., K. Getter, B. Behe, J. Harte, and E. Almenar. 2012. Influences of packaging attributes on consumer purchase decisions for fresh produce. Appetite 59(2):270-280.

Kuchler, F., C. Greene, M. Bowman, K.K. Marshall, J. Bovay, and L. Lynch. 2017. Beyond nutrition and organic labels-30 years of 
experience with intervening in food labels. 5 Mar. 2020. <https://ageconsearch.umn.edu/ record $/ 291967 />$.

Kuhns, A. and M. Saksena. 2017. Millennials devote larger shares of their grocery spending to prepared foods, pasta, and sugar and sweets than other generations. Amber Waves 1-10.

Kumar, A. and S. Smith. 2018. Understanding local food consumers: Theory of planned behavior and segmentation approach. J. Food Prod. Mktg. 24(2):196-215.

Lampkin, N.H. 1994. Organic farming: Sustainable agriculture in practice. The economics of organic farming-An international perspective. CAB International, Oxon, UK.

Loureiro, M.L. and S. Hine. 2002. Discovering niche markets: A comparison of consumer willingness to pay for local (Colorado grown), organic, and GMO-free products. J. Agr. Appl. Econ. 34(3):477-487.

Low, S.A., A. Adalja, E. Beaulieu, N. Key, S. Martinez, A. Melton, and B.B.R. Jablonski. 2015. Trends in US local and regional food systems. Research Report 128. U.S. Department of Agriculture, Economic Research Service, Washington DC.

Lusk, J.L. 2018. Separating myth from reality: An analysis of socially acceptable credence attributes. Annu. Rev. Resour. Econ. 10:65-82.

Macke, D. 2016. Marketing to Millennials - US - May 2016. 5 May 2020. <https://store.mintel.com/ marketing-to-millennials-us-may-2016>.

Meas, T., W. Hu, M.T. Batte, T.A. Woods, and S. Ernst. 2014. Substitutes or complements? Consumer preference for local and organic food attributes. Amer. J. Agr. Econ. 97(4):1044-1071.

Ness, M., M. Gorton, and S. Kuznesof. 2002. The student food shopper: Segmentation on the basis of attitudes to store features and shopping behaviour. Brit. Food J. 104(7):506-525.

Onozaka, Y. and D.T. McFadden. 2011. Does local labeling complement or compete with other sustainable labels? A conjoint analysis of direct and joint values for fresh produce claim. Amer. J. Agr. Econ. 93(3):693-706.
Panzone, L., D. Hilton, L. Sale, and D. Cohen. 2016. Socio-demographics, implicit attitudes, explicit attitudes, and sustainable consumption in supermarket shopping. J. Econ. Psychol. 55:77-95.

Roster, C.A., L. Lucianetti, and G. Albaum. 2015. Exploring slider vs. categorical response formats in web-based surveys. J. Res. Pract. 11(1): 1 .

Seemiller, C. and M. Grace. 2018. Generation Z: a century in the making. Routledge, New York, NY.

Sirieix, L., M. Delanchy, H. Remaud, L. Zepeda, and P. Gurviez. 2013. Consumers' perceptions of individual and combined sustainable food labels: A UK pilot investigation. Intl. J. Consum. Stud. 37(2):143-151.

Smith, G. 2008. Does gender influence online survey participation? A record-linkage analysis of university faculty online survey response behavior. ERIC Document Reproduction Service No. ED 501717.

Spence, A. 2005. Using implicit tasks in attitude research: A review and a guide. Soc. Psychol. Rev. 7:2-17.

Stegelin, F.E. 2002. Food and the millennial generation. J. Food Distrib. Res. 33(1):182-184.

Su, C.J., C.K. Tsai, M. Chen, and W. Qing Lv. 2019. US sustainable food market generation $z$ consumer segments. Sustainability 11(13):3607.

Thach, E.C. and J.E. Olsen. 2006. Market segment analysis to target young adult wine drinkers. Agribusiness: Intl. J. 22(3):307-322.

Torres, A.P. and M.I. Marshall. 2018. Identifying drivers of organic decertification: An analysis of fruit and vegetable farmers. HortScience 53:504-510.

Torres, A.P., M.I. Marshall, C.E. Alexander, and M.S. Delgado. 2016. Are local market relationships undermining organic fruit and vegetable certification? A bivariate probit analysis. Agr. Econ. 48:1-9.

Twenge, J.M. 2017. IGen: Why today's superconnected kids are growing up less rebellious, more tolerant, less happy-and completely un- prepared for adulthood-and what that means for the rest of us. Atria Books, New York, NY. USDA-ERS. 2019. US diets are out of balance with Federal recommendations. Edited by USDAERS, Washington, DC.

USDA-NASS. 2019. 2017 Census of Agriculture. USDA-NASS, Washington, DC.

Vecchio, R. and A. Annunziata. 2013. Consumers' attitudes towards sustainable food: A cluster analysis of Italian university students. New Medit. 12(2):47-56.

Vega-Zamora, M., F.J. Torres-Ruiz, and M. ParrasRosa. 2018. Key determinants of organic food consumption: The case of olive oil in Spain. HortScience 53:1172-1178.

Verain, M.C.D., J. Bartels, H. Dagevos, S.J. Sijtsema, M.C. Onwezen, and G. Antonides. 2012 Segments of sustainable food consumers: A literature review. Intl. J. Consum. Stud. 36(2): 123-132.

Vilella-Vila, M., J. Costa-Font, and E. Mossialos. 2005. Consumer involvement and acceptance of biotechnology in the European Union: A specific focus on Spain and the UK. Intl. J. Consum. Stud. 29(2):108-118.

Wedel, M. and W.A. Kamakura. 2012. Market segmentation: Conceptual and methodological foundations. Vol. 8. Springer Science \& Business Media, New York, NY.

Wills, J.M., D.B. Schmidt, F. Pillo-Blocka, and G. Cairns. 2009. Exploring global consumer attitudes toward nutrition information on food labels. Nutr. Rev. 67(1):102-106.

Yue, C., C. Grebitus, M. Bruhn, and H.H. Jensen. 2010. Marketing organic and conventional potatoes in Germany. J. Intl. Food Agribus. Mktg. 22(1-2):164-178.

Yue, C. and C. Tong. 2009. Organic or local? Investigating consumer preference for fresh produce using a choice experiment with real economic incentives. HortScience 44:366-371.

Zepeda, L. and D. Deal. 2009. Organic and local food consumer behaviour: Alphabet theory. Intl. J. Consum. Stud. 33:697-705. 